\title{
EDUCAÇÃO NÃO FORMAL: A IMPORTÂNCIA DO EDUCADOR SOCIAL NA CONSTRUUÇÃO DE SABERES PARA A VIDA EM COLETIVIDADE
}

\author{
Joselaine de Araujo ${ }^{1}$, Caroline Kraus Luvizotto ${ }^{2}$ \\ ${ }^{1}$ Discente do Programa de Mestrado em Educação da UNOESTE. ${ }^{2}$ Docente do Programa de Mestrado em \\ Educação da UNOESTE. E-mail: ilainearaujo@hotmail.com
}

\section{RESUMO}

A educação não formal pode ser definida como um espaço de formação para a construção de aprendizagens de saberes necessários para a vida em coletividade, sobretudo por meio do trabalho do educador social. O objetivo deste artigo é caracterizar a ação do educador social por meio da investigação do seu perfil profissional junto ao projeto socioeducativo Projovem Adolescente no Município de Presidente Prudente/SP. A metodologia da pesquisa está pautada nas técnicas de análise bibliográfica, análise documental e entrevistas, enquanto elementos da pesquisa qualitativa. No campo prático, junto ao projeto em tela, o educador social cumpre o papel de facilitar a trajetória de cada jovem e do coletivo de jovens na direção do desenvolvimento pessoal e social, contribuindo para o desenvolvimento de um ambiente educativo, participativo e democrático.

Palavras-chave: Educação não formal, Educador social, Aprendizagem, Construção de saberes, Coletividade.

\section{NON-FORMAL EDUCATION: THE IMPORTANCE OF SOCIAL EDUCATOR IN BUILDING THE KNOWLEDGE FOR LIFE IN COMMUNITY}

\begin{abstract}
Non-formal education can be defined as an educational space for the construction of knowledge necessary for life in community, through the work of the social educator. The aim of this paper is to characterize the action of the social educator by investigating their professional profile with the project Projovem Teenager in the city of Presidente Prudente /SP. The research methodology is guided in the techniques of literature review, document analysis and interviews, as qualitative elements. In the practical field, with the design on screen, the social educator plays the role of facilitating the trajectory of each young person and the collective youth toward personal and social development, contributing to the development of an educational, participatory and democratic environment.

Keywords: Non-formal education, Social educator, Learning, Knowledge construction, Collectivity.
\end{abstract}




\section{INTRODUÇÃO}

Ao se pensar em educadores sociais, percebe-se que o seu trabalho tem mais do que finalidades individuais óbvias, tem utilidade social. A formação contínua tem como finalidade última o aperfeiçoamento pessoal e social de cada educador, numa perspectiva de educação permanente. Mas, tal aperfeiçoamento tem um efeito positivo no sistema educacional, pois culmina na melhoria da qualidade da educação oferecida às crianças e adolescentes matriculados nos projetos socioeducativos, em condição complementar à escola.

Diante do exposto, o objetivo deste artigo é caracterizar a ação do educador social por meio da investigação do seu perfil profissional junto ao Projovem Adolescente, enquanto um projeto socioeducativo, no Município de Presidente Prudente/SP.

Dessa forma, o problema que orientou a construção da pesquisa se expressa por meio de questões inter-relacionadas que tratam da educação não formal, do trabalho do educador social e a necessária formação pedagógica neste contexto que permitiram descrever a atuação do educador social junto ao projeto e que conduziram as decisões de pesquisa, sobretudo, respondê-las à luz do caráter científico.

A metodologia da pesquisa apresentada cumpre a intenção de acordo com as contribuições de Lüdke e André (1986) no sentido de promover o confronto entre os dados, as evidências, as informações coletadas sobre 0 assunto e o conhecimento teórico acumulado a respeito das peculiaridades da prática didáticopedagógica do educador social em um projeto de educação não formal, no Município de Presidente Prudente/SP. Um dos desafios foi empregar corretamente os métodos de investigação, pautados nas técnicas de análise bibliográfica, análise documental e entrevistas, enquanto elementos da pesquisa qualitativa.
Ao apresentar os resultados da pesquisa e as respectivas análises, destaca-se que as análises levaram em consideração: o espaço onde se concretiza a educação não formal, a própria caracterização deste processo educativo e a prática didático-pedagógica do profissional enquanto docente.

\section{EDUCAÇÃO NÃO FORMAL}

A reflexão acerca da educação não formal parte do entendimento de que nas diversas faces da educação na sociedade há aquela que não se realiza no espaço da escola, mas é complementar a ela, desenvolve processos de aprendizagens e construção de saberes por meio de vivências e relações prazerosas no processo de ensino-aprendizagem. Nessa linha de reflexão há um conceito de educação que possibilita compreender a dimensão da proposta da educação não formal.

O termo educação abrange um
universo que extrapola os muros
da escola, instituição com papel
central na formação dos
estudantes que por ela passam,
principalmente no que diz
respeito ao acesso aos
conhecimentos historicamente
sistematizados pela sociedade.
As especificidades da
educação, no seu sentido mais
amplo, são muitas. Entre elas a
educação não formal, uma
modalidade que vem ocupando
um espaço significativo no
cenário nacional e que, por isso,
vem merecendo atenção por
parte de diferentes segmentos
da sociedade. (VON SINSON,
PARK; SIEIRO, 2001, p. 9)

Percebe-se, nos últimos tempos, um avanço nas discussões acerca dessa concepção de educação, sobretudo quando se encontra respaldo na própria Lei de Diretrizes e Bases da Educação Nacional (LDB) promulgada em 1996, sob o número 9.394 , em que a reconhece como ações e processos educativos aqueles desenvolvidos por movimentos sociais e 
organizações da sociedade civil, nos quais a educação não formal prevalece.

Segundo Gohn (2006), na educação não formal, além da intencionalidade e proposta curricular, ela também capacita os indivíduos a se tornarem cidadãos do mundo, no mundo. Sua finalidade é criar oportunidades de conhecimento sobre o mundo que circunda os indivíduos e suas relações sociais. Seus objetivos são construídos, inclusive por meio do processo interativo, gerando um processo educativo.

Semelhante ao que se propõem às práticas escolares, a educação não formal deve ser percebida como um tipo de proposta complementar a educação escolar. Assim, deve ser definida como um espaço concreto de formação para a aprendizagem de saberes relacionados à vida em coletividade. Ainda é possível afirmar que este tipo de educação permite que o sujeito que dela participa seja capaz de agir em seu contexto histórico e social, sobretudo no sentido de transformação por meio de reflexão.

De acordo com Von Sinson, Park e Sieiro (2001), os espaços de educação não formal devem visar ao desenvolvimento social, assim como favorecer a participação coletiva, inclusive da comunidade. Além de procurar compreender a educação não formal como uma atividade organizada cujos objetivos são construídos com a intenção de construir um processo educativo, vale compreender a atuação do educador social neste contexto por meio da participação da sociedade civil.

Em cada campo de atuação da educação há um profissional atuando para que o processo de ensino-aprendizagem se efetive. Na educação não formal, este profissional é o Educador Social.

A dinâmica do ato de educar é esta: quando nos aproximamos do que o outro busca em termos de conhecimento no ato da procura. O educador é apenas um facilitador que se coloca à disposição do outro sem cobrar necessariamente dele a resposta. Nesse processo, não existe certo ou errado, existem apenas as possibilidades de desenvolvimento de cada um, em intensidade particular e subjetiva, processo de construção de conhecimento que vai se modelando na medida escolhida por cada um dos atores que se permitem adentrar no caminho do autoconhecimento pela interrelação (CUNHA apud VON SINSON, PARK, e SIEIRO, 2001, p. 203).

De acordo com Gohn (2010) na ação profissional o principal instrumento de trabalho do educador social é o diálogo. Não o simples "jogar conversa fora", mas o diálogo tematizado, estruturado com base nas propostas das atividades. Somam-se a ele 0 estudo de fundamentos teóricos e a prática de atividades que visam a uma formação integral do sujeito, não apenas aquela relacionada ao avanço dos aspectos cognitivos.

Trata-se de um perfil em que associadas as suas competências, habilidades e atitudes, ou saberes profissionais, o trabalho do educador social deve ter, sem dúvida, uma boa dose de espontaneidade, mas pautado em princípios e metodologias de ação, que incluem estudo de indicadores socioculturais e econômicos, contextualização da comunidade no conjunto das redes sociais e temáticas de um município e pesquisa histórica.

\section{PROJETO PROJOVEM ADOLESCENTE E O PAPEL DO EDUCADOR SOCIAL}

Com base nas definições contidas no Traçado Metodológico (BRASIL, 2008) e Caderno de Concepções e Fundamentos (BRASIL, 2009) o Projeto "Projovem Adolescente", está voltado para jovens na faixa etária de 15 a 17 anos de famílias beneficiárias pelo Programa Bolsa Família, bem como de jovens vinculados ou 
egressos de programas e serviços da proteção social especial, como o Programa de Combate à Violência e à Exploração Sexual e o Programa de Erradicação do Trabalho Infantil (PETI), ou ainda jovens sob medidas de proteção ou socioeducativas previstas no Estatuto da Criança e do Adolescente.

No campo prático o educador social cumpre o papel de facilitar a trajetória de cada jovem e do coletivo juvenil na direção do desenvolvimento pessoal e social, contribuindo para a criação de um ambiente educativo, participativo e democrático. Sua competência engloba planejar, organizar e executar as ações socioeducativas, especialmente os encontros de cada coletivo, bem como integrar os demais profissionais da equipe ao planejamento geral do serviço socioeducativo, articulando e integrando todas as ações.

Os encontros constituem de momentos que acontecem duas vezes por semana, entre os educadores sociais que desempenham a função de orientador social e os jovens nos bairros, denominados territórios. Os jovens participam de acordo com a localização de sua residência em relação ao território. Nestes encontros as atividades visam 0 aprofundamento nos conteúdos vinculados aos temas transversais por meio de pesquisas, reflexões, estudos, debates dentre outras ações.

As oficinas são momentos em que se realizam práticas de esporte, cultura, recreação e/ou lazer. Acontecem duas vezes por semana e delas participam os jovens sob a mediação de um facilitador, ou seja, educador social com experiência ou formação na respectiva área. De acordo com o Traçado Metodológico (BRASIL, 2008), as oficinas são espaços de vivências que reforçam os valores éticos e o compromisso dos jovens com o projeto.

Entender as características do projeto em tela permite entender os resultados da pesquisa com os educadores sociais em exercício no Projeto Projovem Adolescente no Município de Presidente Prudente/SP. Portanto, são apresentados alguns dados descritivos para visualizar o perfil de educadores participantes desta investigação.

Os dados serão apresentados considerando a faixa etária, o vínculo no projeto socioeducativo, o processo seletivo ao qual foi submetido e sua experiência profissional. Não serão apresentadas, entretanto, as identidades destes profissionais cujos nomes serão preservados e substituídos por letras com prefixo "EDUC.".

Dentre os oito educadores sociais entrevistados, três são educadores físicos do sexo masculino, os quais desempenham a função de facilitadores sociais. Os demais educadores são do sexo feminino e desempenham a função de orientadoras sociais.

Todos os educadores possuem formação na educação superior, concluída ou em fase de conclusão e, sobretudo, todas na área de Ciências Humanas. Com exceção da Educ. A que tem formação em administração com grau de bacharelado, os demais são licenciados ou se preparam para a licenciatura, demonstrando opção profissional para atuar com a docência.

Partindo para a análise da pesquisa com os educadores sociais, quando questionados sobre as complexidades do seu cargo, as educadoras responsáveis pelos encontros foram unânimes ao enfatizar as necessidades e dificuldades de aprendizagens escolares apresentadas pelos educandos. Tais necessidades fazem emergir uma segunda complexidade para seu trabalho: "driblar" a falta de interesse dos educandos que tentam "disfarçar" a enorme dificuldade de leitura e escrita.

Para tanto, quando a questão norteadora está relacionada à necessidade de formação em 
Pedagogia como requisito desejável para atuar como educador social a percepção dos entrevistados é que de fato a formação precisa ser na área de educação, com curso superior em andamento ou concluído em licenciatura. $\mathrm{Na}$ tentativa de responder se de fato a educação não formal complementa a ação da escola, os resultados da pesquisa demonstram que os educadores sociais estão buscando continuamente superar as complexidades e desafios do cargo, por meio de constantes aprendizagens e troca de experiência, bem como consideram em sua prática as diretrizes metodológicas do projeto que, mesmo tratando de serviço socioeducativo, insere no projeto conteúdos, conhecimentos, práticas e sistemas de desenvolvimento, acompanhamento e avaliação dos sujeitos em consonância a educação formal, desenvolvida no contexto da escola.

Assim, considerando o referencial teórico que fundamenta este trabalho o educador social cumpre o papel de facilitar a trajetória de cada jovem e do coletivo juvenil na direção do desenvolvimento pessoal e social, contribuindo para a criação de um ambiente educativo, participativo e democrático. Neste campo prático, a competência docente engloba planejar, organizar e executar as ações socioeducativas, especialmente os encontros de cada coletivo (grupo), bem como integrar os demais profissionais da equipe ao planejamento geral do serviço socioeducativo, articulando e integrando todas as ações.

\section{CONSIDERAÇÕES FINAIS}

Neste trabalho, a educação também é abordada como meio de inclusão social e percebida nos depoimentos referentes às práticas dos educadores sociais entrevistados. Inclusão entendida como alternativa de promover o acesso do jovem à participação cidadã. A compreensão, a partir de então, de que o educador social precisa desenvolver saberes docentes que orientem suas práticas a partir de formação específica, definindo seu papel na realização das atividades, reconhecendo as características e necessidades dos educandos e, não apenas cumprindo, mas também estudando e refletindo sobre os processos de planejamento, avaliação, sistematização e instrumentos de acompanhamento e registro de suas ações.

É possível indicar que dentre as aprendizagens, a mais significativa com esta pesquisa, foi reconhecer a importância da educação não formal no processo de construção de uma sociedade mais justa e democrática, por meio da atuação do profissional educador social. Foi possível enfatizar a formação pedagógica do educador social como sendo de extrema importância para cumprir o seu papel, o qual the exige profissionalmente, 0 domínio de determinados conteúdos, o conhecimento de práticas pedagógicas e dos os processos e procedimentos dos serviços socioeducativos.

Concluí-se este texto na perspectiva conceitual de Gohn (2010) que trata da educação não formal como uma ferramenta importante no processo de formação e construção da cidadania, neste caso, dos educandos. Processo este, de educação, entendido pelo desenvolvimento com coletivos e preocupado com a construção de aprendizagens e saberes. Mesmo que tratando a educação não formal comparando-a a educação formal, a perspectiva foi abordá-las como mecanismos de inclusão social. Falamos de uma educação que exige uma atitude do educador, que pressupõe a necessidade de uma adequada formação acadêmica, significativa vivência profissional e saberes docentes que o aproximem dos adolescentes na construção de conhecimentos. 


\section{REFERÊNCIAS}

BRASIL. Ministério do Desenvolvimento Social e Combate à Fome. Adolescências, juventudes e socioeducativo: concepções e fundamentos. Brasília: Ministério do Desenvolvimento Social e Combate à Fome, 2009.

Ministério do Desenvolvimento Social e Combate à Fome. Traçado metodológico. Programa Nacional de Inclusão de Jovens PROJOVEM. Brasília: Ministério do Desenvolvimento Social e Combate à Fome, 2008.

GADOTTI, M. A questão da educação formal/não formal. Sion (Suisse), 18 au22oct2005. Disponível em: $<$ http://www.paulofreire.org/pub/Institu/Sublnstituci onal1203023491/t003Ps002/Educacao formal na o formal 2005.pdf>. Acesso em: 19 set. 2010.

GOHN, M. G. Educação não formal e o educador social: atuação no desenvolvimento de projetos sociais. São Paulo: Cortez, 2010. (Coleções questões da nossa época; v. 1).

Não-fronteiras: universos da educação não formal. São Paulo: Itaú Cultural, 2007. 96 p.

LÜDKE, M.; ANDRÉ, M. E.D.A. Pesquisa em educação: abordagens qualitativas.São Paulo: EPU, 1986.

VON SINSON, O.R.; PARK, M. B.; FERNANDES, R. S. (orgs). Educação não-formal: cenários da criação. Campinas, SP: Editora Unicamp/Centro de Memória, 2001. 